stein-Jensen culture, however, was positive for Mycobacterium bovis.

A course of antituberculous chemotherapy using ethambutol and rifampicin was started. Chest and lumbar spine radiographs showed no other foci of infection, but several further collections required aspiration from around the hip. Pain increased and radiographs 16 months after initial presentation showed evidence of loosening of both components (Fig. 2); it was decided to proceed to a Girdlestone arthroplasty.

At operation, both components were loose and thorough debridement of the hip was carried out. There was no evidence of secondary infection, and tissue specimens were sterile on routine culture and on Lowenstein-Jensen culture for Mycobacterium bovis. Discussion. Buchholz et al (1981) and Carbon et al (1981) each reported two cases of tuberculous infection of hip replacements, but we were able to find no recorded cases of infection by bovine tuberculosis. In our patient we were unable to find any other foci of tuberculous infection, past or present. Treatment with drugs and by surgical excision of the joint appears to have eradicated the infection.

No benefits in any form have been received or will be received from a commercial party related directly or indirectly to the subject of this article.

\section{REFERENCES}

Buchholz HW, Elson RA, Engelbrecht E, et al. Management of deep infection of total hip replacement. J Bone Joint Surg [Br] $1981 ; 63$ B:342-53.

Carbon C, Brion NV, Darcy M, Thomas M, Lamotte-Barrillon S. Tuberculous infection of total hip prosthesis: report on two cases. Ann Méd Interne 1981 ; 132:124-5.

\title{
SURGERY FOR CURLY TOE DEFORMITY: A DOUBLE-BLIND, RANDOMISED, PROSPECTIVE TRIAL
}

\section{A. J. HAMER, D. STANLEY, T. W. D. SMITH}

Several operative procedures have been described for the treatment of curly toes in children. It is a relatively common deformity which may be related to intrinsic muscle paresis, although this could not be clearly demonstrated by Taylor (1951). Surgical treatment may be by flexor-to-extensor tendon transfer, as originally described by Girdlestone (Taylor 1951), to overcome the presumed weakness of the intrinsic muscle pull, or by simple flexor tenotomy, for which good results have been reported by Ross and Menelaus (1984).

There have been retrospective studies comparing the two procedures in children and in adults (Pyper 1958; Parrish 1973; Pollard and Morrison 1975) but we are not aware of any double-blind, randomised, prospective trials. We therefore present a four-year follow-up of 46 toes randomised to either flexor tenotomy or flexor-toextensor tendon transfer.

Patients and methods. We recruited 19 patients requiring surgery for bilateral curly toe deformity after obtaining fully informed consent from their parents. No child had any gross neuromuscular pathology. Each patient had

A. J. Hamer, FRCS, Registrar in Orthopaedic Surgery

D. Stanley, FRCS, Consultant Orthopaedic Surgeon

T. W. D. Smith, FRCS, Consultant Orthopaedic Surgeon

Department of Orthopaedic Surgery, Children's Hospital, Western Bank, Sheffield S10 2TH, UK.

Correspondence to Mr A. J. Hamer.

(C)1993 British Editorial Society of Bone and Joint Surgery

0301-620X/93/4R85 \$2.00

J Bone Joint Surg [Br] 1993; 75-B :662-3.

Received I December 1992; Accepted 12 January 1993 the same toes affected on both feet and similar degrees of deformity. Those on one foot were allocated at random to receive either a flexor tenotomy or a flexor-to-extensor transfer; the corresponding toe on the other foot then received the other operation. The patients and their parents were not informed which operation was performed on each toe, but they were told that the medical literature indicated that neither was superior.

The technique of flexor-to-extensor transfer was that described by Taylor (1951) and credited to Girdlestone, except that only the long flexor tendon was transferred. We did not use a Lambrinudi splint or plaster cast. A dorsolateral incision was made from the level of the metatarsophalangeal joint to the distal interphalangeal joint. The extensor expansion was exposed, and the long flexor tendon identified, caught in a blunt hook, divided, brought around the lateral aspect of the proximal phalanx, and sutured through the extensor hood by a buttonhole method.

The incision and operative steps were identical for the toes undergoing flexor tenotomy, except that the suturing of the flexor tendon to the extensor expansion was omitted.

After operation all the patients had wool and crepe bandage support for the first few days and were allowed to bear weight as soon as this was possible.

Photographs of the feet were taken with the patient standing. Of the 19 patients, preoperative photographs were available for seven. Postoperatively, 13 patients were reviewed at four years and assessed clinically by one of the authors $(\mathrm{AJH})$, without knowledge of the 


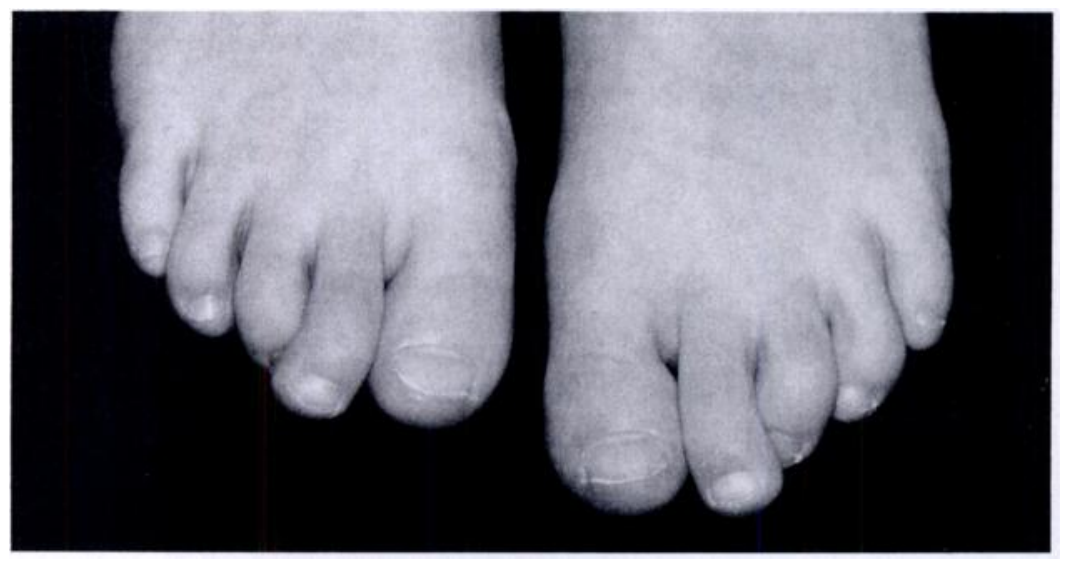

The feet of one patient before operation, to show the different grades of deformity. The right third toe is grade 3 , and the left third toe is grade 2. Both fourth toes are grade 1 .

Fig. 1

procedure carried out on each toe. The opinion of the patient and the parents was recorded, and an assessment of the success or otherwise of the procedures was made.

Toes were graded according to the degree of deformity (Fig. 1): grade 0 , no deformity; grade 1 , mild curl with or without adduction and with or without rotation; grade 2, as grade 1 but with some overriding of the adjacent toe; and grade 3, as grade 2 but with increased fixed flexion so that the toe nail was not visible from the dorsum of the foot.

Chi-squared tests were used to compare the grades of deformity between the groups preoperatively and postoperatively.

Results. The 19 patients had their operations between February and November 1988, and review was undertaken in May and June 1992. Five patients could not be traced, and one parent replied by letter that there had been no problems. The remaining 13 patients ( 23 pairs of toes) were reviewed. There were 22 third toes, 22 fourth toes and two fifth toes.

Table I. Results of surgery for curly toe deformity

\begin{tabular}{llllll}
\hline & \multicolumn{2}{l}{ Flexor tenotomy } & & \multicolumn{2}{l}{ Tendon transfer } \\
\cline { 2 - 3 } $\begin{array}{llll}\text { Preoperative } \\
(\mathbf{n}=\mathbf{1 2})\end{array}$ & $\begin{array}{l}\text { At four years } \\
(\mathbf{n}=\mathbf{2 3})\end{array}$ & $\begin{array}{l}\text { Preoperative } \\
(\mathbf{n}=\mathbf{1 2})\end{array}$ & $\begin{array}{l}\text { At four years } \\
(\mathbf{n}=\mathbf{2 3})\end{array}$ \\
\hline 0 & 0 & 17 & 0 & 11 \\
1 & 5 & 6 & 5 & 12 \\
2 & 4 & 0 & 6 & 0 \\
3 & 3 & 0 & 1 & 0 \\
\hline
\end{tabular}

*see text

The detailed results are given in Table $\mathrm{I}$. The mean age at surgery was 7.3 years ( 3 to 14). There was no significant difference in the preoperative grades between the two groups, and at four years there was no significant difference between the postoperative grades $(p<0.5$, $>0.1$ ). The results were generally good, no child having any symptoms at follow-up, and all were satisfied with the correction. The mean grade for all toes was 1.75 preoperatively and 0.39 postoperatively. One child had required fusion of the distal interphalangeal joint for fixed flexion deformity one year after the initial procedure, which was a flexor tenotomy.

Discussion. The numbers in our trial were small, but sufficient for it to be clear that the deformities were much improved four years later, and that the choice of procedure made no difference. We did not compare our cases with a non-operated group, and it is possible therefore that spontaneous improvement may have occurred, although this has not been described.

Our results indicate that tenotomy of the long flexor of the toe is the important part of the operation and that transfer of the divided tendon to the extensor of the toe is unnecessary. Flexor tenotomy is not usually performed through a dorsolateral incision, but we consider that this approach is acceptable, since it leaves almost invisible scars.

No benefits in any form have been received or will be received from a commercial party related directly or indirectly to the subject of this article.

\section{REFERENCES}

Parrish TF. Dynamic correction of clawtoes. Orthop Clin North Am 1973; 4:97-102.

Pollard JP, Morrison PJM. Flexor tenotomy in the treatment of curly toes. Proc R Soc Med 1975; 68:480-1.

Pyper JB. The flexor-extensor transplant operation for claw toes. $J$ Bone Joint Surg [ Br] 1958; 40-B:528-33.

Ross ERS, Menelaus MB. Open flexor tenotomy for hammer toes and curly toes in childhood. J Bone Joint Surg [Br] 1984; 66-B:770-1.

Taylor RG. The treatment of claw toes by multiple transfer of flexor into extensor tendons. J Bone Joint Surg [Br] 1951 ; 33-B :539-42. 